\title{
Non-Indigenous Women Teaching Indigenous Education: A Duoethnographic Exploration of Untold Stories
}

\author{
Sarah Burm \\ Western University \\ Dawn Burleigh \\ The University of Lethbridge
}

\begin{abstract}
Identifying as non-Indigenous, we are often left considering our positionality and identity in Indigenous education, how we have come to be invested in this area of research, and what we see as our contribution. In conversation with one another, we realized we choose to share certain stories and not others about our experiences working in Indigenous education, but were less familiar with why, after working in the field for a sustainable period of time, we felt the need to censor our stories. What did we fear might happen if we divulged these 'untold' stories? What follows is a duoethnographic inquiry that seeks to attend to this question. We have chosen to dialogically document, analyze, and probe our experiences as teacher-educators in Indigenous education to unpack why we refrain from sharing certain experiences we have encountered since becoming involved in teacher education. By responding to this question through duoethnographic writing we hope to broaden how we come to understand and extract meaning from our experiences working in the area of Indigenous education.
\end{abstract}

Keywords: Indigenous education, duoethnography, teacher education, dialogic reflection

Sarah Burm, Ph.D., is a Research Education Innovation Specialist at the Centre for Education Research \& Innovation (CERI) at Western University. She is also an Ontario certified teacher with experience teaching at the K-12 level as well as at the post-secondary level.

Email: sarah.burm@schulich.uwo.ca

Dawn Burleigh, Ph.D., is an Assistant Professor in the Faculty of Education at the University of Lethbridge. Her research and teaching interests include, Indigenous teacher education and the work of teachers in Northern and remote communities.

Email: dawn.burleigh@uleth.ca 
It was while living and teaching in a remote First Nations community in northern Ontario where we shared with one another our experiences, insights, and reflections concerning schooling for Canada's First Nations, Metis, and Inuit (FNMI) students and our position as non-Indigenous people involved in this work. Looking back, we spent a lot of time talking about our teaching experiences, remembering the students who walked through our classroom doors. Over lunch, after school, at a weekend potluck or on the phone with family and friends, we would recall an incident that occurred at school; our response, student reactions, and lessons learned. Some stories were told with pride or laughter while others brought out our individual insecurities and at times, even feelings of negativity and hopelessness.

Those conversations did not end when we boarded the airplane for summer holidays at the end of each school year. Nor did they stop when we finally left the community where we started our teaching careers. And they especially did not end when we each made the decision to pursue graduate studies in Indigenous education. Our conversations continued, intensifying. However, what was different now was our position within the story. We were no longer situated within the story. Rather, we gazed retrospectively back at ourselves, as though we were watching our experiences, ourselves from a bird's eye view. We developed an awareness of the stories we told and began to attend to what our experiences, our stories taught us.

\section{Arriving at the Inquiry}

The negotiation of our roles was explored thoroughly in a paper titled Unpacking our White Privilege: Reflecting on our Teaching Practice (Burleigh \& Burm, 2013). In that paper we respond to the question "What is it like to teach in a remote First Nations community?" This initial inquiry was fueled by our desire to further preservice teachers' understandings of teaching Indigenous students. During that inquiry we realized we choose to share certain stories and not others when asked about our continued involvement within Indigenous education. What did we fear might happen if we divulged these 'untold' stories? What follows is a duoethnography (Norris, Sawyer, \& Lund, 2012) that attends to this critical question. We have chosen to dialogically document, analyze, and probe our experiences as teacher-educators in Indigenous education to unpack why we refrain from sharing certain experiences, challenges, and dilemmas we have encountered since becoming involved in teacher education.

\section{Encountering the Problem}

While designing a conceptual framework for this paper, we realized we told different versions of the same story depending on who asked and in what context. This became especially apparent when we each taught an Indigenous education course within a mid-size university in southwestern Ontario. This course, offered as an elective to teacher education candidates, was designed to help pre-service teachers examine the social, political, and historical impacts of Indigenous education in Canada. Throughout the course, teacher education candidates were encouraged to engage in ongoing, critical reflection around what they knew about teaching Indigenous students, and how their own assumptions and understandings about Indigenous communities, issues, and perspectives informed their development as professional educators. Students critically engaged in discussions on such topics as the intergenerational impact of the residential school system, decolonization, white privilege, and power, all while considering their own positions and perspectives in relation to these topics. This can be heavy, emotional work, and often these topics were abstract and difficult for some students to grasp. It was not uncommon for us to share certain stories from our 
teaching and research practice as a means to mitigate student resistance or anxiety. Our stories served as a gateway to introduce issues sensitive in nature.

Students listening to our stories reacted to them, participating in a sense, in the action of the narratives we told. As they began understanding the many barriers to education that impact Indigenous learners (Battiste, 2013; Cannon, 2012; Gordon \& White, 2014; Hare, 2011; Paquette \& Fallon, 2008), they wondered why we continued dedicating time and effort to this work. Others were curious to learn more about our experiences as non-Indigenous women working in this field, the impact it has had on how we come to understand ourselves and our role in the conversation concerning Indigenous education in Canada. Similar interactions would occur in the presence of our colleagues, or our families and friends. Anytime issues concerning Indigenous Peoples were raised or the question "What do you do?" was posed, we found ourselves emphasizing, modifying, or even omitting certain people, places, and events from our responses, careful not to divulge too much information. Other times we remained silent, unsure what the appropriate response might be given the milieu we found ourselves in.

\section{Utilizing Duoethnography}

\section{Methodology}

We turn to duoethnography (Norris, 2008; Sawyer \& Norris, 2013) in our efforts to critically examine our tendency to share certain stories over others when asked about our continued involvement in Indigenous education. A relatively new research genre, duoethnography is a collaborative research methodology whereby a team of researchers utilize storytelling to simultaneously generate, interpret, and articulate data in order to co-engage in meaning making around a particular phenomenon (Norris, Sawyer, \& Lund 2012; Sawyer \& Norris, 2013). The authors voices are made explicit as readers witness them in conversation with one another. The approach is deeply personal and introspective; each researcher pushing the other to engage critically and reconceptualise their perceptions around the topic at hand (Norris, Sawyer, \& Lund 2012). Given the dialogic nature of this mode of inquiry and the conducting of research 'with' and not 'on' another (Kovach, 2009), it was important for us to enter into this research endeavour with someone where a relationship of trust and respect was firmly established. As teacher-educators, we have more than 10 years' experience working in the field of Indigenous education. Collaborating on a self-study exploring how we broach the subject of our cultural identities as nonIndigenous people felt almost necessary if we expected students to do the same. (Nicol \& Korteweg, 2010). Our draw to duoethnography was the opportunity it afforded to confront the "multiplicity of perspective" (Sawyer \& Norris, 2016, p. 8) flowing throughout our entangled story. Engaging in dialogic reflection was an opportunity to interrogate our cultural assumptions, and revisit those pivotal 'untold' stories we purposely abstained from sharing with others.

\section{Collecting Data}

Data collected focused on our involvement in Indigenous education since entering the university context as doctoral students to the transition to early career teacher-educators. These data included discussions we had with one another spanning five years which, within that time, we each started and finished doctorates in Indigenous education, taught a preservice course, and developed relationships with Indigenous organizations and community members within our 
respective communities. We also drew on individual journal entries kept during this time whereby we began to articulate our perceptions, ask questions, and make connections to one another's insights and interpretations of encounters we had both in and out of academic, encounters that left us questioning how we position ourselves and our stories in the context of the work we do. The culmination of these experiences and critical conversations are comprised here into four stories, each in a different setting: the academic, the social, the insider (the stories we share with each other) and, self (the stories we tell ourselves). We utilize these stories to unpack and delve deeper into the potential fears and reasons we reshape and reframe the stories we tell.

We casted ourselves as the main characters in each of the four stories and generated dialogues to make explicit how our stories over the years have varied depending on who we are speaking to and in what context. We created a series of composite characters representing individuals with whom these stories involve. Italicized text indicates our internal dialogue, what we are thinking and not saying in interactions with others. Rather than artificially disassociating the analysis from our autobiographical stories, we have chosen to integrate the discussion and analysis throughout the remainder of the paper. We conclude by outlining three teaching approaches that have helped us move beyond the limitations we found in ourselves and in our stories.

\section{The Academic}

\section{Telling Our Stories}

Dialogue. At conferences, in the hallways, and during committee meetings we are often confronted with questions about our teaching practice. What follows is a dialogue representative of the many interactions we have had both individually and together that highlight some of the tensions we encounter as new scholars in the field of Indigenous education. After a particularly challenging class where students appeared resistant to explore their own privilege and positionality, Sarah sets off down the hall and as she turns the corner, sees Beth, another Faculty member in Education:

Beth: Hello Sarah. How are you doing? How are your classes going this term? I am hearing really good things about your Indigenous Education class from some of our teacher candidates.

I knew I should have went the other way! She caught me off guard and I am melting into the walls, in hopes that I disappear and that she will just keep walking.... I'll just wait a few seconds .... nope she is still talking to me. Ok, time to formulate a response.

Sarah: "Hello Beth. How are you? Yes, the classes seem to be off to a good start. The students appear to be engaged and are asking a lot of great questions. I am really enjoying teaching this class so far."

Thank goodness she can't hear what is going on inside my mind. I would much rather respond with something like, "Well Beth, my students seem particularly resistant to exploring their own privilege and how that might impact their positionality as teachers. My students can't process their privilege and it is so frustrating to watch. However, I am not sure that's a conversation you are interested in having right now."

Beth: So how has it been for you teaching the Indigenous students in the class seeing as you are not Indigenous? 
Really, I can't believe she is asking me this. Perhaps now is not an appropriate time to get into the politics and optics of who the Indigenous students are in our Faculty of Education. Let's not get into the politics of self-identification right now in the hallway. And this course isn't JUST for the students who self-identify as Indigenous is it? What about the non-Indigenous students and increasing their levels of cultural awareness and sensitivity? I am reminded yet again of the lack of cultural sensitivity this Faculty carries. I wish I could say all of what I am thinking aloud rather than letting these thoughts ruminate in my head, but that wouldn't be professional of me now would it? So after a few head nods and a short pause to signal that I am thoughtfully crafting a response I answer with:

Sarah: It's been a great opportunity to model for students how a non-Indigenous person can and should be engaged in this field of education. One of the real goals of the course is to increase students' confidence and comfort levels so that they see themselves doing this work.

Beth: That's great Sarah. You are doing fine work.

Sarah's self-reflection. I always hold my breath slightly when I am at a faculty meeting, a staff luncheon, or beginning a new class term and I am asked the question, "What do you do?" I never know where I am supposed to begin. How far back do I go? How much do people really want to hear? Do I tell them I am doing research in the field of Indigenous education? Usually this information leads to a curious look on people's faces. They stare harder, their eyes burning into me trying to figure out why someone non-Indigenous is involved in such work. Do I tell them I once taught in a First Nations community? Revealing this information usually causes the dumbfounded look on people's faces to fade. Depending on the venue I either propel forward with this fact or I hold onto it for a moment, slipping it into my pocket for when I need to prove my legitimacy. I introduce myself as non-Indigenous but I find some discomfort in the non-piece. I feel it excludes, divides me, perhaps even distancing me from the work that I do. I am easily made uncomfortable by other's questions. How do I both present my legitimacy, my motivation for working in Indigenous education while being honest with myself and others that I am still very much a learner alongside them?

\section{The Social}

Dialogue. We both have had various school and professional experiences, and as a result of those we have created lasting and important friendships. Tibby represents a culmination of our experiences and conversations with friends in social situations. Over lunch the usual conversation about family and social updates has been taken care of and the focus turns to work. Tibby, an ever caring and invested friend begins to inquire about how Dawn's work is coming along.

Tibby: How are things going with your work Dawn? What's new?

Dawn: Things are good. Busy with work and school as usual. Sarah and I are writing a paper right now and we are focussing on how we respond in different ways to different people when asked questions related to our field of study. It has been really interesting. It is nice because it provides us with an opportunity to really look at how our writing and thinking remains colonial in some 
ways. We always struggle with our roles in Indigenous education as non-Indigenous people you know?

Tibby: Oh right - so we are saying Indigenous now and not Native or Aboriginal - I cannot keep up with what they prefer to be called. I am not even sure what some of those words mean - hahaha - that's good you are writing with Sarah because you need that for publishing right - so how is Sarah doing? I saw on Facebook that she had been on a road trip and done some hiking?

Dawn: She is good. Busy with school and stuff too but she has been doing lots of travelling. We are going to a conference in a few weeks so we might do some shopping when we are there. It should be fun.

I am going to completely avoid any details about what I am specifically working on at this time. Would Tibby want to know or understand the anti-colonial position of teacher retention in First Nation communities, or the funding gaps and achievement gap that dictate the literature I have been reading? Probably not. So rather than expand, I deflect all questions about my research and work and move on to more neutral territory - shopping.

Dawn's self-reflection. At BBQ's, birthdays, and basically any social gathering I attend I am often asked, "So how is work going?" I consider how I might reply. Constructing this reply requires a quick but deep analysis of who is asking and what they really want to know. At this point I hope my phone will ring, that someone reaches for me or joins the conversation and changes the subject. Avoidance, delay and outright redirection are usually my initial responses to this question.

It is often difficult to respond in a meaningful way for a number of reasons. First, I dread that a comment or statement will be made that deeply offends me and could potentially compromise the relationship I have with that person. What would I do if a close friend of 25 years made a racist comment? Rather than explore the possible outcomes of that scenario I avoid it all together. Do you need help with those dishes? I can help! Do you need a hand preparing dinner? I can help! I will help with anything rather than detail my experiences. I assume whoever asks doesn't really want to know. I assume they are just trying to engage me, humor me, or entertain me to be polite. I assume they don't care. I assume if I really talked about what I was working on or thinking that they would grow uncomfortable because what I talk about might require them to assess their own privilege, question the stereotypes they hold and seek to understand rather than be understood. It is clear that my perception in social interactions are riddled with assumptions: I don't want to inconvenience others, or disrupt the status quo but then I leave feeling like a fake, like I am perpetuating the status quo. Why in these social situations am I so careful not to disrupt?

\section{The Insider (The Stories we Tell Each Other)}

Dialogue. We have been friends, colleagues, and co-authors for several years and as a result, phone calls are often blended conversations between personal and professional stories. Teaching similar courses across the country have made for some interesting conversations about the parallels and differences between provincial politics and the needs of students and school communities. Below is a phone call that details a common teaching experience. 
Dawn phones Sarah:

Dawn: Hey. So I was teaching today and the whole idea about not doing Indigenous work because I don't have Indigenous students in my class came up yet again.

Sarah: Oh dear. What happened?

Dawn: Basically I have a group of about 20 students, some are First Nations and Metis but most are non-Indigenous and we were talking about how to incorporate Indigenous perspectives and content into the curriculum. Specifically, we were talking about using story books by Indigenous authors at the elementary level and a few of the students seemed really disengaged. So I went up to them and tried to get a dialogue going and they were saying, "I will be teaching here in town. I won't have any Indigenous students in my class so I would not need to use these types of books." Ugh it is so annoying.

Sarah: This issue keeps coming up. I have had the same discussion in my class and I can't help but feel slightly defeated when this question is asked. Like all of the work we have done in class up to this point has gone over their head. Anyway, how did you respond?

Dawn: Yeah, I hear you. We spent the first four or five weeks of class talking about positionality, assumptions in education, and white privilege and that was a challenge enough. The students were initially resistant because they had to think through some difficult and uncomfortable things. But, at some point I felt like we had made progress. When we talked about settler Canadians and the role of treaties, I felt like I had made the case for why incorporating Indigenous perspectives, content, and resources is needed.

Sarah: Yes, but Dawn, both you and I know that talking about white privilege and examining white privilege are two different things. And we have to acknowledge that by teaching courses such as this we hold a certain position of power as teachers and as non-Indigenous people that cannot be taken for granted.

Dawn: I had my students read The Invisible Backpack by Peggy Mcintosh and we did an activity called Cross the Line where if students had experienced one of the items on Macintosh's list, they would cross the line. It made a very clear case that some students in the class had certain privileges and others didn't, specifically related to race. I saw students who were white step over the line and look back at the Indigenous students and other non-white students in the class who didn't step over the line. There was a clear distinction. I think they can understand it theoretically but when it comes to how it looks in the classroom they, and I, hit a roadblock.

Sarah: It is like we are having to almost persuade our students that white privilege is real, all while working within a system that unfortunately operates through a colonial, Eurocentric framework. We are trying to decolonize our class but the influence of conflicting messages continues to push back against our best efforts. At times like this I think we both need to take a step back and remind ourselves what brought us to this work in the first place. Why is doing Indigenous education important to us? Why does this matter to us? We wouldn't keep returning to this topic if it didn't matter to us in some way. 
Dawn: True. I think I realized that for me now, the reason I still do this is not only because of my past teaching experience up North but because I want students here in the Faculty of Education to carry this work on. I had a moment in my class this term that was very different than any other class I have taught. I was teaching in a curriculum and instruction class and all my students had majors in Native American Studies (NAS) so they came to me with a really good grasp of Indigenous issues so we had a different starting point. One day we had an Elder come to class and he talked about their experiences in school. We invited another class who were not NAS majors to join the discussion. The debrief conversation was amazing! At one point a student asked the same question we are talking about right now. The student basically said, "Why would I need to do any of this if I don't have Indigenous students in my class? I teach science so there isn't really room for Indigenous perspectives to be incorporated." There was a moment of silence in the room and I hoped someone would respond to this student. Slowly I saw a student raise her hand. A typically quiet student, she actually stood up and addressed the question. She basically said, "You not only have a responsibility to incorporate Indigenous perspectives, because it is provincially required and it is in the curriculum, but you also have a responsibility as a settler Canadian. You have a stake in treaties as do all of our students. It's not about having Indigenous students or not. In fact non-Indigenous students might need to know this more." Wow. I was blown away. The NAS students were able to respond to the questions of the other non NAS students really well. It was one of the rare times where I felt like I was standing amongst allies and didn't have to convince anyone about why this work is necessary and important.

Sarah: That's incredible that your student felt comfortable enough to stand up in class and make such a strong statement. And it is true. We all have a stake, an obligation to do this work but unless our preservice students have those one on one interactions with people where personal stories are shared, they won't understand why this work is so important and needed. In class I often feel like I have hooked them, like they have seen the light, so to speak, but I am always worried that their responses to me are just lip service. Do they say they get it just so that I get off their back? What happens when they walk out those classroom doors?

Dawn: I think about the sustainability of it too. What will students do in a year, three years or even five years? It's hard to know what impact has been made if any. I think strategically, the strongest way to have an impact is to ensure the actual curriculum is more inclusive of Indigenous issues and perspectives. And of course create more understanding within Faculties of Education so the message is somewhat consistent across programming.

Sarah: Yes, I agree. I tell myself that maybe what we discuss in class may not matter to my students now, but some day, in some interaction they have, be it in a classroom or in the checkout line at the grocery store, they will reflect back and draw some sort of connection and hopefully be more empathetic towards others, not believe everything they hear and just learn to listen more.

Dawn: I hope so too. I am sure we will continue to talk about this again. I teach in 10 minutes so maybe I will call you after class with a new story. Talk to you soon.

Sarah: There is always something to talk about isn't there? Have a good class.

Dawn: Always. Talk to you soon. Bye 
Dawn: Oh shoot - I only have 10 minutes. I need to grab chart paper and markers and all the lesson plan assignments that need to be handed back. Off I go. Hopefully the students are feeling good today. I know they were a bit down last week with all the tensions around white privilege. I will need to get them engaged again. Sarah asked why this was important to me, and why we keep doing this work. I don't know if I stop enough to really think through what my own response to these questions are. What is my response to myself? It should be the most important but I think it's the response I think about the least.

Sarah: I hang up the phone with Dawn and despite having a hundred things to get done by the end of day, my thoughts go back to our phone conversation and the questions I posed. What brought us to this work in the first place? Why does this matter to us? Why does this matter to me? I think about these questions a lot and often it is difficult to put into words why this work matters, why I am involved in this work. Just as my students are working through these difficult questions so am $I$.

\section{The Self (The Stories we Tell Ourselves)}

Dawn: The story I tell myself is quite possibly the simplest of all. I am invested in Indigenous education because when I was a high school teacher I felt the challenges my students experienced and somewhere inside of me I knew it wasn't fair. Inequitable funding, oppression, loss of language and culture, assimilation - all through the education system. I saw the impacts on my students and how it shaped their experiences of school. I realized that as a teacher I was implicated within this system. I needed to understand more and I am still doing that many years later.

My response to how I feel about doing this work as a non-Indigenous person is not simple at all. The intention may be clear and simple but the carry through is wrought with complexities about place, space, identity, legitimacy, and allyship. I know this is a path for me and every day I move along that path sometimes being redirected by different people or my own reflections. I remind myself to be patient and be ready for what I need to know when I will most need to know it. I realize now I model this journey for my students and try to make it explicit, often inviting students to join me. Everyday poses new challenges and new opportunities and with those I will continue to think about why this is important to me. This is only a partial response, one that might not ever be complete, but it is the beginning that will grow with time and for now I remain comfortable with the uncomfortability of it all.

Sarah: I look back at the person I was in those first couple years teaching in northern Ontario and I don't recognize her. I am amazed at how little she knew and wonder what impact her ignorance and complacency might have had on her young students. Other times I am angry, appalled that she didn't know more. Even now I am continuously in awe at how little people know about Canada's Indigenous peoples, at how unaware or apathetic people are to another's experience of inequity because of who they are and where they come from. How do people turn and simply look the other way? She is/I am not able to look away anymore.

Now that I teach new teachers who are just beginning their careers I am more sympathetic toward her, knowing that she and I are a product of a system that privileges certain ways of knowing over others. The hesitation, the fear of making a mistake, the desire to learn more but unsure of when enough is enough--these are the questions and comments I hear constantly from my students. I tell them I understand, that I have heard her/myself respond in the same way. I tell them their good intentions will go a long way, that people will be there to help guide them, 
encourage them, that people will be kind to them. Providing these words of comfort and encouragement puts my students at ease; it gives them hope. They need to hear these words. There are times however when hearing such words is not enough. A positive sentiment can't take away the heaviness that weighs on my shoulders and heart after hearing another's story of trauma and abuse. Hearing students confide to me that they don't feel safe in school because of their cultural background nearly brings me to tears. There is no knife sharp enough to cut through the tension that has filled the rooms of meetings I have attended between Indigenous and non-Indigenous people around what Indigenous education is, what it can be, why it is important. It is often tiring, emotional work. I have days where I grow frustrated with how slowly things seem to change. Yet, I know too that this journey is lifelong. That where I am today is different from where I was yesterday and where I will be tomorrow. There is an ebb and flow to the work that requires me to trust others and myself and I will continue on this journey.

\section{Discussion}

\section{Unpacking our Stories}

Through our writing, we realized the stories we shared previously were ones where we felt most comfortable; those where a happy ending was always guaranteed and where our audience was left feeling hopeful about the future. We avoided the embarrassing, awkward, and upsetting stories but were less clear as to why we censored ourselves. We have brought forward one perspective of those uncomfortable stories here. We face the avoidance and censoring and acknowledge the constraining boundaries.

\section{Avoiding and Censoring}

Avoidance was a strong tactic used in our academic and social interactions. We were not engaging in dialogue or conversation with our colleagues or friends but rather avoiding one. In fact, we utilized exit strategies to disengage and remove ourselves from the spaces where these conversations occurred. These strategies were enacted most often when we sensed possible conflict or disagreement.

In these interactions we often censored what we said and how we said it when the conversation turned to our involvement in Indigenous education. One strategy of censorship we utilized was pre-determining at what point to begin a conversation. Our pre-determinations were based on a number of assumptions about the person we were conversing with. How much do they already know? What positions do they hold? What were their beliefs? What were their intentions and what was their purpose in beginning a conversation with us in the first place? And most importantly, what was our existing relationship with this person? We were more consciously aware of this behaviour in our interactions with friends and family but less so when interacting with colleagues. For example, in the social story, Dawn quickly averted the conversation with Tibby when Dawn perceived tensions around terminology. This was not only an avoidance tactic but a strong indication of censorship to the degree of silencing ourselves. We noticed these behaviours most often in our social interactions where long-standing, valuable relationships could be compromised. These themes are limiting to our position as instructors in Indigenous education and as allies to Indigenous agendas. We need to see social and academic interactions as proactive opportunities and invitations rather than reactive exits and endings. 


\section{Constraining Boundaries}

We feel empowered in our teaching practices and in conversation with one another but why does empowerment not extend to the hallway conversation with Beth or the informal conversations with Tibby? We found deeply rooted connections with our own educational experiences as students and then as teachers all in predominantly western institutions. We learned early on in our own schooling experiences that the work of teachers takes place in classrooms and schools. So, when our work as teachers and researchers extended beyond classroom walls, we often felt unsure about how to proceed and as a result, we avoided and censored. The classroom environment became a safe space and site for engagement and ongoing professional development. Unfortunately this engagement and empowerment is often limited to the classroom versus the hallways or out for coffee with friends because those spaces are traditionally not perceived as sites for learning. Institutional norms also impact how we see our role. The university measures what counts and what matters in course units and in instructional hours. We see now that there are amazing teaching and learning opportunities that extend beyond the classroom. Rather than seeing these spontaneous encounters as something to avoid, we need to push beyond the institutional constraints and our conceptions of where and when teaching and learning can occur.

\section{Conclusion}

We began this inquiry by asking what we feared might happen if we divulge our untold stories. In order to critically engage with the stories we tell, we utilized four conversational sites in which we regularly interact: the academic, the social, insider, and self. In the academic and social interactions, censorship and avoidance were tactics we employed to prevent potential conflict or misunderstanding. Through listening and sharing these stories with one another, we found what we fear most is compromising relationships, including our relationship with ourselves. A greater fear lies in compromising our integrity, and silencing ourselves to the point where we are unable to embody allyship in Indigenous education. This implores us to seek new strategies beyond censorship and avoidance.

\section{Recommendations}

With an increased focus on national reconciliation efforts, (Truth and Reconciliation Commission of Canada, 2015), faculties of education are being called on to improve their programming and better attend to Indigenous perspectives. This effort, out of necessity, must include both Indigenous and non-Indigenous students and educators. Hansen and Antsanen (2016), emphasize the connection between the inclusion of Indigenous perspectives in education and the ongoing colonial experience. They recommend:

expanding Indigenous teachings devoted to raising awareness of social and cultural issues to the non- Indigenous community who could also benefit from a non-Eurocentric Indigenous education curricula. Without these governmental supports, Indigenous people will continue to experience racial stereotyping, social exclusion, and marginalization in the wider society. (p.15)

Moving beyond censorship and avoidance is necessary, not only to improve our practice as teachers, but to better attend to and engage in reconciliation efforts. In our own teaching, we raise 
students' and our own consciousness utilizing three general strategies; low-risk role play, community integrated involvement, and partnerships.

Low-risk role play strategies create experiential opportunities for students to explore sensitive but important concepts like oppression and privilege. The blanket exercise (Kairos Canada, 2017) is an excellent low-risk teaching tool where students interactively build understanding about our shared history as Indigenous and non-Indigenous peoples in Canada. Community integrated involvement is another approach which shifts the locus of knowledge to members of the local community. Inviting guest speakers into your class or arranging visits to significant local sites are all opportunities for students to experience the specificity of various Indigenous contexts. These experiential learning opportunities are essential for disrupting any preconceived assumptions or stereotypes held by students. Lastly, early engagement with Indigenous leaders and communities, both within and beyond the academy is the foundation that will set the tone for long term sustainability. These relationships must reside on a sincere commit to trust and learn from one another. Only then will we be better able to engage our students and empower ourselves to move beyond the avoidance and censorship that has so often dictated the stories we tell. 


\section{References}

Battiste, M. (2013). Decolonizing education: Nourishing the learning spirit. Vancouver, BC: Purich Publishing Ltd.

Burleigh, D., \& Burm, S. (2013). Unpacking our white privilege: Reflecting on our teaching practice. In Education, 19(2), 107-119.

Cannon, M. J. (2012). Changing the subject in teacher education: Centering Indigenous, diasporic, and settler colonial relations. Cultural and Pedagogical Inquiry, 4(2), 21-37.

Gordon, C. E. \& White, J. P. (2014). Indigenous educational attainment in Canada. The International Indigenous Policy Journal, 5(3), 1-28.

Hansen, J. G. \& Antsanen, R. (2016). Elders' teachings about resilience and its implications for education in Dene and Cree communities. International Indigenous Policy Journal, 7(1), $1-17$.

Hare, J. (2011). The way of the warrior: Indigenous youth navigating the challenges of schooling. Canadian Journal of Native Education, 34(2), 93-111.

Kairos Canada. (2017). What is the blanket exercise? Retrieved from https://www.kairosblanketexercise.org/

Kovach, M. (2009). Indigenous methodologies: Characteristics, conversations, and contexts. Toronto, ON: University of Toronto Press.

Norris, J. (2008). Duoethnography. In L. M. Given (Ed.), The SAGE encyclopedia of qualitative research methods (pp. 233-236). Los Angeles, CA: SAGE.

Norris, J., Sawyer, R. D., \& Lund, D. (Eds.). (2012). Duoethnography: Dialogic methods for social, health, and educational research. New York: Routledge.

Nicol, C., \& Korteweg, L. (2010). Braiding teacher lives into relation: The steps and dilemmas of culturally responsive teacher education in Canada. In A. Heinz (Ed.), The eighth international conference on self-study of teacher education practices (pp. 183-187). Provo, Utah: Brigham Young University.

Paquette, J. \& Fallon, G. (2008). First Nations education and the law: Issues and challenges. Education Law Journal, 17(3), 347-378.

Sawyer, R. D., \& Norris, J. (2013). Duoethnography. New York, NY: Oxford University Press.

Sawyer, R. D., \& Norris, J. (2016). Dialogic interdisciplinary self-study through the practice of duoethnography. In R. D. Sawyer \& J. Norris (Eds.), Interdisciplinary reflective practice though duoethnography: Examples for educators (pp. 1-14). New York: Palgrave Macmillan.

Truth and Reconciliation Commission of Canada. (2015). Honouring the truth, reconciling for the future: Summary of the final report of the truth and reconciliation commission of Canada. Retrieved from http://nctr.ca/assets/reports/Final\%20Reports/Executive_Summary_English_Web.pdf 